\title{
Towards a Model of Rehabilitation Technology Acceptance and Usability
}

\author{
Mohammad Hatami Kaleshtari, Ileana Ciobanu, Petre Lucian Seiciu, Andreea Georgiana Marin, and \\ Mihai Berteanu
}

\begin{abstract}
Creating the best solution in terms of a rehabilitation technique, device or system design for rehabilitation medicine interventions or assistance is not enough. The new solution has to be effective. And, in order to be effective, it has to be used therefore, the solution has to be accepted by the user as a solution for his/her functional need. The solution must convince the physical therapist, all the other members of the medical team, as well as the patient and his/her family, of its utility, before use and during its use. The degree of usability of the solution will be cultural specific and very personal. A model for Rehabilitation Technology Acceptance and Usability (RTAU) has been developed in order to become a base for rehabilitation technology usability prediction. The model presented in this paper is a world-wide premiere, considering the patient centered approach.
\end{abstract}

Index Terms—Rehabilitation technology, usability.

\section{INTRODUCTION}

New technologies are continuously introduced in rehabilitation medicine clinical practice and some of them are used along with the old ones. In 2005, in Israel, for example, a questionnaire based survey detected the most used technologies in rehabilitation medicine facilities. Monitoring of the sitting position in the wheelchair was the least used ( $15.4 \%$ occurrence), while virtual reality had an occurrence of $42.3 \%$. The question arising is which technology has in fact of higher clinical importance, which one is the most usable, and which one should be part of the standard equipment for a rehabilitation medicine facility [1]? From Ambient Assisted Living (AAL) Joint Projects, 70\% are left in experimental model or prototype phase. We talk about the issues related to the transfer of these technologies from the lab to the clinical practice, about their level of acceptance and usability in a given context, by real users with different degrees of disability [2].

Manuscript received April 21, 2015; revised June 5, 2015. This work was supported by a grant of the Romanian National Authority for Scientific Research, CNDI- UEFISCDI, project number 190/2012, as well as by COST Action TD1006 European Network on Robotics for NeuroRehabilitation. This paperwork is sustained by the Sectorial Operational Program - Human Resources Development (POS DRU), project co-financed by the European Social Fund and by the Government of Romania under the agreement no. POSDRU/159/1.5/S/137390.

M. Hatami Kaleshtari, A. Marin, M. Berteanu, and I. Ciobanu are with the Rehabilitation Department of Elias University Hospital, Carol Davila University of Medicine and Pharmacy of Bucharest, Romania (e-mail: mberteanu@gmail.com, ileanacuk@yahoo.co.uk).

P. L. Seiciu is with Politehnica University of Bucharest Romania, Machine Elements and Tribology Department, Faculty of Mechanical Engineering and Mechatronics, Romania (e-mail: lucian.seiciu@as.info.ro).

\section{USABILITY CONCEPTS AND CONSTRUCTS}

Human behavior is defined by the cloud of mannerisms and physical actions of the individuals. It encompasses voluntary and involuntary acting, innate or learned/acquired reactions to a complex of conscious and subconscious processing of external and internal data, emotion and energy. Consumer behavior is difficult to predict, even for experts in this domain [3].

There is need of a real consensus of several determinants in order to make a potential user to adopt a new technology. The previous positive experience with technology, one's cognitive and practical abilities, activated by motivation and faith in good results and some amount of sense of adventure will push the user towards a positive decision concerning the acceptance of a new technology. Trust in the provider, as well as the needed degree of social pressure will get together with the personal impulse, ensuring the success of the acceptance demarche for the new technology. Once accepted, the new technology waits to be used.

Consumer Behavior - The Black Box Model. The black box model of the consumer behavior has been developed, in relation to the black box theory of behaviorism. Consumer behavior is the generic term to indicate the way individuals and organizations select, secure, use and dispose of products, services and ideas in order to satisfy their needs, as well as the impact of this behavior upon the user itself and the society [4]. An achievement process comprises 5 stages: the identification of the need, the search for information, the balance of the options, the choice (the decision making), and the achievement of the product/service [5]. The individual's perception of the world is the one defining his/her beliefs and orienting his need identification and evaluation, as well as his choice. Creating a personal database concerning the technology available, the potential user will evaluate the alternatives and their complex costs. The potential user will process a decision, will integrate that decision, making it part of himself/herself. After that, he/she will engage in the chosen buyer/consumer/user behavior [6]. To use or not to use - that is the question!

Usability is a term defined by the easiness of learning to use and the easiness of using any object/device/system/application created by man. The International Organization for Standardization (I.O.S.) defines usability as: The extent to which a product can be used by specified users to achieve specified goals with effectiveness, efficiency and satisfaction in a specified context of use [7]. There have been several attempts to create an appropriate construct meant to allow a quantification of 
usability. Jakob Nielsen and Ben Schneiderman describe in the composition of usability the following elements: the easiness of learning how to use the system, the easiness of memorizing the use of the system, the efficiency of using the system, the error level (number of errors done by the user, how serious are these errors, how easy is for the user to recover after error) and the level of user satisfaction concerning the use of the system [8]. Tetard and Collan proposed a "Lazy User Model" as a pattern for choosing a new technology. This model explains that the user will always adopt the solution requiring a minimal effort from the user, providing a maximum of efficiency, at the same time [9].

Technology Acceptance Model - TAM is a theory concerning the adoption of informational systems which explain the process behind the adoption of a new technology. This theory states that "perceived utility" (defined by Fred Davis as the degree of performance a user thinks he/she will achieve by using the technology) and "the subjective easiness in using the system" (defined by Fred Davis as the degree of effortlessness a user attributes to using the system) are the factors determining the adoption of a new technology [10].

TAM has been studied and developed continuously, leading to the, "Unified Theory of Acceptance and Usability of Technology", (UTAUT - Venkatesh et al, 2003). The most recent version of UTAUT (Venkatesh and Bala, 2008) considers the risks of using the informational systems, too. UTAUT states that performance expectancy, effort expectancy and social influence are the factors which determine the behavioral intention, triggering the use behavior, in facilitating conditions. Gender, age, experience and voluntariness of use modulate the key factors, age and experience representing themselves facilitators or obstacles for the intention to use and user behavior [10]. Usability is highly related to the level of the objective efficiency and effectiveness of using technology, as well as to the subjective level of satisfaction of the user (concerning the easiness of the use learning process, the friendliness of the device-user interface, the working process itself, and the results of it concerning the progress of the impairments and the decreasing in the user's disability level, in the case of rehabilitation technology) [11]. Extremely important is the attitude the potential user has towards technology broadly speaking, and for the specific gender of technology at hand. The behavioral intention to adopt new technology is affected by six beliefs: provider's commitment, the compatibility, perceived difficulty, adaptive experiences, enhanced values and perceived benefits [12]. Previous experience generates a related attitude. Gender is also important, males showing generally more positive attitudes towards high technology, no matter how experienced they are they; females' attitude gets more positive as the level of familiarity increases. Age is important too: young people are more susceptible to accept new technology than elder.

Challenging technologies are more likely to be adopted by individuals with higher cognitive abilities, reasoning and mechanical skills [13].

\section{TOWARDS A MODEL OF REHABILITATION TECHNOLOGY ACCEPTANCE AND USABILITY}

Assessing Usability. The authors of the present paper used in 2011-2012 the UTAUT questionnaire in order to predict and to evaluate the usability of a high tech persuasive "coach" designed to improve the physical activity level of patients with chronic obstructive pulmonary disease. The rehabilitation medicine team's expectations weren't too high. The results of the study indicate that, motivated to improve their health condition and given an appropriate support, the subjects were willing to experience the use of a new technology, not only in lab conditions, under the surveillance of health care professionals, but also at home, during one month field trial. Even those unfamiliar with high tech devices had successfully used the system, and even the suspicious ones improved their status using the system, getting a change of their own attitude towards this kind of technology and its capacity to be helpful in a rehabilitation program. The users highly appreciated the system's feedback concerning physiological parameters, as a safety measure [14], [15].

Disability is an umbrella term, describing a situation in which, in certain conditions, the individual cannot perform optimal functioning and participation concerning certain fields of activity. The world perception of these users is altered according to their specific impairment and perceived quality of life. One developing a rehabilitation technology must understand what happens in the black box of his potential user. Disability comes with complete functional alteration. The entire person suffers. None of us can completely cope with disability. Exhaustion depression appears gradually and cognitive abilities have a negative trend. Even personality changes. Frustration due to inability to perform the previous activities (or the activities the others can perform) and the marked tendency of living the „object loss" comes along with decreased self-esteem and self-confidence, an emotional void accompanies the narrowing of horizon and the thinning of the sense of coherence, and defensive behaviors evolve (especially the complainant/accuser mode) [16]-[18]. Rehabilitation medicine fights disability using two different approaches: a compensative approach and a restorative approach. The results of the clinical studies indicate that the use of assistive technology helps actual rehabilitation and the dividing line between these two categories begins to vanish. As the palette of the rehabilitation technology tools becomes larger and larger, appears the necessity of benchmarking the usability of these tools [19]-[21].

The studies concerning the rehabilitation technology mainly assess the clinical efficacy of the systems (the same way as for medication) and the studies concerning the assistive technology are concerned mainly of user's satisfaction. There is nothing about the objective usability of these devices. Juan Victores et al. consider that the potential users of rehabilitation technology must be involved in all the phases of the development of an assistive robotic system, their feedback concerning the system's capabilities and usability being fundamental. Searching the literature, they concluded that the studies published up to that moment lack consistency concerning methodology and are mainly if not only concerned about user-system interface accessibility [22]. 


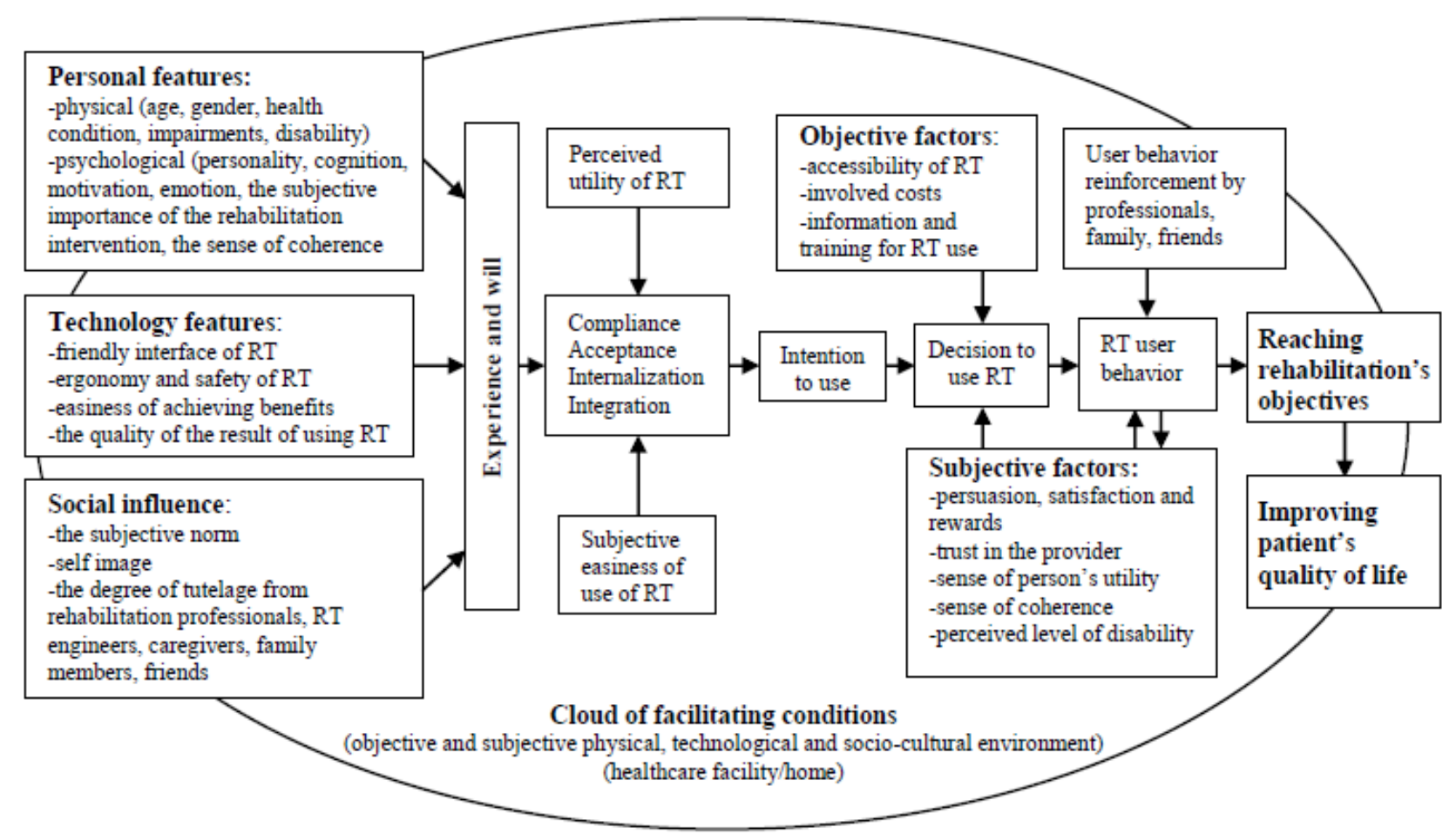

Fig. 1. Rehabilitation technology acceptance and usability (RTAU) patient centered approach (PCA) model.

Function or Feeling? The results of a survey indicate that "9-10\% of Ohio wheelchair users find it extremely difficult or impossible to use a wheelchair for necessary daily activities and $40 \%$ of wheelchair users report difficulty or impossibility with many steering and maneuvering tasks". A study design using focus group and a scenarios based questionnaire indicates the need for safety-related and integrated telehealth features to be built-in new smart chair technology. Lesser interest has been shown by the potential users concerning the intrusiveness of this technology [23]. Initially accepted, many devices are abandoned, sooner or later. Christopher J. Grasso, after a laborious systematic search in literature, cites Verza (2006), who identified a series of factors determining abandonment of assistive technology: poor user input in device selection, change in a user's needs or worsening of physical functioning, poor device performance, durability or reliability, lack of training (or lack of ongoing support), complexity of the device (confusing for users and caregivers), fatigue or discomfort while using the device [24]. In order to develop long term usable assistive technology, one must consider both the motor and cognitive abilities and needs of a person and the social and emotional needs of the potential user, in a more personal centered approach. Scherer, cited by Grasso, says: "The device should contribute to a positive identity, improve self-esteem, and enhance their quality of life". Thomas W. King [25] emphasizes ten specific human factors that relate to the development of assistive technology (AT) (and we may extrapolate, to rehabilitation technology): transparency of the device (user friendliness and visibility), cosmetics of the device (cultural specific), mapping of AT learning, use and operation, affordances (visual cues to the use), learned/taught helplessness, feedback from the device, knowledge of AT "in the head and in the world", constraints of AT use, incorporation of failsafe functions, prevention of errors in
AT use.

\section{REHABILITATION TECHNOLOGY ACCEPTANCE AND USABILITY (RTAU) MODEL}

After a study based on a non-formal interview (to avoid Hawthorne's effect) [26] on the beliefs and expectations of the rehabilitation medicine professionals and of our patients, in conjunction with the experience from previous research on different rehabilitation technology and patients' and professionals' satisfaction, our interdisciplinary team conceived a model concerning the acceptance and usability of rehabilitation technology, using as basis the UTAUT construct frame. Fig. 1 presents the new Patient Centered Approach (PCA) Model developed by the authors. The complex process of acceptance and use of RT is broken into sequences. From compliance with the RT, to the established user behavior, each phase of the process is subject to objective and subjective, individual and environmental influences and takes place in a specific ,reaction environment" where different conditions may have the role of catalysts, stimulators or inhibitors. Each step of the process is accompanied by feedback to and changes in experience and will, personal features and perceived utility and ease of use, enhancing the dynamic process of integration, and empowering the user with motivation and skill in RT use. The functional gains are stimulated, and the sense of self confidence and coherence of the patient is reinforced. The process of developing RT itself is a chain of iterations and user feedback entries [26].

We may add to this list the requirements of emotional design and affective technology: positivity, recognition, pattern and ways to add personality [27]. A focus group consisting of 12 specialists in Rehabilitation Medicine, Neurobiology, Physical Therapy, Rehabilitation 
Mechatronics - Engineering and Clinical Psychology has been presented with the model of RTAU and the unanimously conclusion was that the model encompasses all the aspects considered for assessing rehabilitation technology usability.

\section{CONCLUSION}

RT must be the instrument that empowers the user to perform what one's personality needs to perform. The potential user's feedback is essential for developing the right solution. The model of RT acceptance and usability developed hereby is a dynamic structure that can be adapted for each rehabilitation technology assessed and for the specific degree of disability of the potential user.

A scalable assessment tool for RT utility will be developed based on the model of RT acceptance and usability. The original Patient Centered Approach (PCA) is beyond the state-of-the-art in RT, thus results a new, original model, presented in this paper as a world-wide premiere.

"...designers often become an expert with the device they are designing. Users are often experts at the task they are trying to perform with the device.” Don Norman (1988)

\section{ACKNOWLEDGMENT}

This work was supported by a grant of the Romanian National Authority for Scientific Research, CNDIUEFISCDI, project number 190/2012, as well as by COST Action TD1006 European Network on Robotics for NeuroRehabilitation.

This paperwork is sustained by the Sectorial Operational Program - Human Resources Development (POS DRU), project co-financed by the European Social Fund and by the Government of Romania under the agreement no. POSDRU/159/1.5/S/137390.

\section{REFERENCES}

[1] H. Ring, O. Keren, M. Zwecker, and A. Dynia, "Use of Medical technologies in rehabilitation medicine settings in Israel," Israel Medical Assoc Journal, vol. 9, no. 10, pp. 713-6, 2007.

[2] R. A. Cooper, B. E. Dicianno, B. Brewer, E. LoPresti, D. Ding, R. Simpson, G. Grindle, and H. Wang, "A perspective on intelligent devices and environments in medical rehabilitation," Medical Eng Phys, vol. 30, no. 10, pp. 1387-1398, 2008.

[3] J. S. Armstrong, "Prediction of consumer behavior by experts and novices," Journal of Consumer Research, vol. 18, pp. 251-256, 1991.

[4] S. Kuester, "Strategic marketing and marketing in specific industry contexts," MKT 301, University of Mannheim, p. 110, 2012.

[5] S. Khosl, "Consumer psychology: The essence of marketing," International Journal of Educational Administration, vol. 2, no. 2, pp 220-220, 2010.

[6] L. R. Kahle and P. V. Florence, "Marketplace lifestyles in an age of social media," 2012.

[7] Information on I.O.S. Ergonomics of Human System Interaction - Part 210. [Online]. Available: http://www.iso.org/iso/home/standards.htm

[8] J. Nielsen and D. A. Norman. (2000). Web-Site Usability: Usability on The Web Isn't a Luxury. [Online]. Available: http://www.cems.uwe.ac.uk/ fjmaddix/bcn/usability

[9] M. Collan and F. Tetard, "Lazy user theory of solution selection," in Proc. the CELDA 2007 Conference, 2007, pp. 273-278.

[10] V. Venkatesh and H. Bala, "Technology acceptance model 3 and a research agenda on intervention," Decision Sciences, vol. 39, no. 2, May 2008

[11] I. Holm, "Ideas and beliefs in architecture and industrial design: How attitudes, orientations and underlying assumptions shape the built environment," Oslo School of Architecture and Design, 2006.
[12] A. A. K. Ming and P. Enderwick, "A cognitive model on attitude towards technology adoption," Journal of Managerial Psychology, vol. 15, no. 4, pp. 266-282, 2000.

[13] D. T. Bill. (2003). Contributing influences on an individual's attitude towards a new technology in the workplace. [Online]. Available: http://www.liquidknowledgegroup.com/Media/ArticleFiles/Contributi ng\%20Influences\%20on\%20an\%20Individual.pdf

[14] M. Berteanu, R. Badea, I. Ciobanu, L. Dumitru, A. Iliescu, and H. Dinu, "Healthier by safe persuasion," Applied Mechanics and Materials, vol. 245, pp. 9-14, 2013.

[15] M. Tabac, H. Hermens, T. Burkow, I. Ciobanu, and M. Berteanu, "Acceptance and usability of an ambulant activity coach for patients with COPD," in Proc. the IADIS Intl. Conference e-Health, 2013.

[16] A. Antonovsky, "The structure and properties of the sense of coherence scale," Social Science \& Medicine, vol. 36, pp. 725-733, March 1993.

[17] International Classification of Functioning. [Online]. Available: http://apps.who.int/classifications/icfbrowser/

[18] World Report on Disability. [Online]. Available: http://www.who.int/disabilities/world_report/2011/en/

[19] I. Ciobanu and M. Berteanu, "Advanced rehabilitation Technology," Applied Mechanics and Materials, vol. 186, pp. 35-45, 2012.

[20] T. Keller and J. Veneman, "Robotics for neurorehabilitation: Current state and future challenges," Applied Mechanics and Materials, vol. 245, pp. 3-8, 2013.

[21] P. Takác, J. Petrovicová, A. Delarque, K. S. Sunnerhagen, V. Neumann V, A. Vetra, M. Berteanu, and N. Christodoulou, "Position paper on PRM and persons with long term disabilities," European Journal of Physical and Rehabilitation Medicine, vol. 50, no. 4, pp. 453-464, 2014.

[22] J. Victores et al. Benchmarking Usability of Assistive Robotic Systems: Methodology and Application. [Online]. Available: http://www.heronrobots.com/EuronGEMSig/downloads/Anchorage/I CRA10-experiments_final_uc3m.pdf

[23] E. A. Madigan and W. S. Newman, "What do users Want from 'Smart' wheelchairs?" Nurs. Inform, vol. 263, 2012.

[24] C. J. Grasso. (2008). Assistive Technology and Activities of Daily Living for Wheelchair Users. [Online]. Available: http://cjgrasso.com/msd-thesis-project

[25] T. W. King, Assistive Technology: Essential Human Factors, ISBN-13: 1998.

[26] R. McCarney, J. Warner, S. Iliffe, R. V. Haselen, M. Griffin, P. Fisher, and I. Warner, "The hawthorne effect: A randomized, controlled trial," BMC Med. Res. Methodol., vol. 7, no. 30, 2007.

[27] J. A. V. Aldecoa. (2014). The New Affective Technologies Come to The Cultural Sector. [Online]. Available: http://www.accioncultural.es/media/Default\%20Files/activ/2014/Adj/ Anuario_ACE_2014/EN/9affectiveTechno_AVazquez.pdf

Mohammad H. Kaleshtari was born in Teheran, Iran in 1969. He was graduated from Carol Davila University of Medicine and Pharmacy of Bucharest, Romania, in 1998. He is specialized in dermatology, with competences in LASER in dermatology, dermatoscopy in dermatology, dermatocosmetology - specialization at Carol Davila University of Medicine in Bucharest, Romania from 2000 to 2005 . He is now a PhD student in rehabilitation medicine at the same university.

He worked in Colentina Clinical Hospital in Bucharest Romania from 2000 to 2005 as a resident physician, in Elias University Hospital in Bucharest, Romania from 2005 to 2010 as a medical doctor in DermatoVenerology, and works in private practice since 2010, as a medical doctor in Dermato-Venerology (Private Practice Office on Dermatology, on Ferdinand Bd. No. 11A, in Bucharest, Romania.). He participated in 6 clinical pharmacology studies and published several articles in international and Romanian national medical journals. He is interested in phototherapy in dermatology.

Dr. Hatami Kaleshtari is a member of the European Academy of Dermato-Venerology and of the Romanian Society of Dermatology. He participates at the Congresses of European Academy of Dermato-Venerology and at the Congresses of the American Academy of Dermatology.

Mihai Berteanu was born in Bucharest, Romania in 1962. He was graduated from Carol Davila University of Medicine and Pharmacy of Bucharest Romania, in 1987. He received his PhD degree in medical sciences. He is a professor in physical and rehabilitation medicine (PRM) from Carol Davila University of Medicine, Bucharest. He as the head of the Rehabilitation Medicine Department at Elias University Hospital in Bucharest, a PhD in Neurological Rehabilitation, with the PhD thesis: "The merit of 
electro-myographic biofeedback in regaining voluntary control of movement, improvement of muscle strength and in the treatment of spasticity".

$\mathrm{He}$ owns 5 national invention patents on devices for medical and neurological rehabilitation and he is author and co-author of 22 books on rehabilitation medicine, and of many articles in national and international publications (22 articles ISI and ISI Proceedings). He was the partner team leader and a scientific investigator in 15 clinical trials, grants and other national and international rehabilitation research projects. He was organizer of National PRM Congresses with International Participation and of International Conferences on mechatronics and robotics (OPTIROB and ICMERA). He is a member of the director committee of COST Action TD1006 - European Network on Robotics for Neuro-Rehabilitation. He was a partner in Erasmus Life Long Learning for Developing a European Master Course in Advanced Rehabilitation Technologies from 2012 to 2014. His main areas of interest consist in human motion and ergonomics, spasticity and pain, assistive technologies and rehabilitation robotics, cognitive rehabilitation and speech disorders therapy, biofeedback and sensing systems, balneology, health education and scientific education of young healthcare specialists.

Dr. Mihai Berteanu is the leader of the Elias Rehabilitation Research Activity, National Representative of PRM specialists at European Union of Specialist Physicians and a board member of World Federation of Neurological Rehabilitation. 